\title{
A PRÁTICA CONTEMPORÂNEA DE TRADUÇÃO COM AUXÍLIO DE SISTEMAS DE MEMÓRIAS E OS LIMITES \\ DA RESPONSABILIDADE DO TRADUTOR
}

Contemporary translation practice aided by
translation memory systems and the limits
of the translator's responsability

Érika Nogueira de Andrade Stupiello*

\begin{abstract}
RESUMO
Este trabalho apresenta uma análise sobre a crescente adoção de ferramentas pelo tradutor contemporâneo que atua em mercados como o da localização. O acelerado ritmo da produção tradutória de textos em formato eletrônico acaba por condicionar a contratação de tradutores à sua capacidade de empregar com eficiência os recursos oferecidos por ferramentas como os sistemas de memória de tradução. Esses sistemas, como idealizados desde sua concepção inicial, possibilitariam a seus usuários aumentar a produtividade e, simultaneamente, padronizar sua produção terminológica. Buscando ir além da visão descritivista predominante nas abordagens dessas ferramentas, apresenta-se um exame de alguns dos pressupostos teóricos que sustentam o uso de memórias de tradução. Pelo prisma desse exame, analisa-se o envolvimento do tradutor com seu trabalho, especialmente quando este é parte de um processo maior de produção e distribuição de informações em meio eletrônico e para públicos diversificados. Por fỉm, são apresentadas considerações sobre as relações consequentes do emprego dessas ferramentas, como aquelas que se constroem entre tradutor/tradução e tradutor/cliente, assim como a extensão da responsabilidade do tradutor que se dedica a desenvolver traduções parcialmente automatizadas.
\end{abstract}

Palavras-chave: tradução; sistemas de memórias de tradução; localização.

* Universidade Estadual Paulista, São José do Rio Preto, São Paulo. 


\begin{abstract}
This paper analyzes the growing adoption of translation tools by the contemporary translator working for markets such as the localization industry. The fast turnaround pace of translation of electronic texts ends up conditioning the employment of translators to their ability to use the resources provided by tools such as translation memories systems efficiently. These systems, as envisioned in their early conception, would allow users to increase productivity and, simultaneously, standardize their terminological production. Seeking to go beyond the predominantly descriptive approaches of these tools, some theoretical assumptions upholding the use of translation memories are examined. From this perspective, the translator's involvement with the work in progress is analyzed, mainly when this professional is part of a larger process of production and distribution of information by electronic means and for diverse audiences. Ultimately, the consequences of the employment of these tools are taken into consideration, such as those between translator/translation and translator/client, as well as the extension of the responsibility of the translator dedicated to developing partially automated translations.
\end{abstract}

Keywords: translation; translation memory systems; localization.

\title{
1. INTRODUÇÃo
}

No mundo atual, cada vez mais economicamente integrado, é nítido o vínculo entre a produção e a disseminação de informações e os meios de propagação, especificamente na atualidade, pela internet. Diferentemente do que ocorria na era anterior ao surgimento da rede mundial de computadores, a busca por conhecimento e informações dá-se hoje de uma maneira mais cômoda e quase instantânea, visto que, na maioria das vezes, o deslocamento físico é dispensado, ainda que o espaço virtual promova a sensação de constante movimento. Outra mudança importante experimentada no mundo conectado eletronicamente diz respeito à liberação da informação de seus portadores. Essa situação, aparentemente comum nos dias de hoje, tem conferido um ritmo muito mais rápido de circulação de notícias e conhecimento do que as situações sobre as quais informam. Como reflete o sociólogo polonês Zygmunt Bauman, "o aparecimento da rede mundial de computadores pôs fim - no que diz respeito à informação - à própria noção de viagem (e de 'distância' a ser percorrida)” (BAUMAN, 1999, p. 22). 
A liberação da necessidade de se percorrer distâncias para o transporte da informação não só permitiu maior acessibilidade à mesma em diferentes partes do mundo, mas também diminuiu consideravelmente seu custo. Hoje, com a internet, paga-se uma tarifa de ligação local para se obter acesso mundial. Uma das consequências dessa redução de custo está no aumento excessivo do montante de informações, especialmente se considerarmos que "comunicação barata significa o rápido transbordamento, sufocamento ou atropelamento da informação obtida, assim como a chegada veloz de notícias" (BAUMAN, 1999, p. 23). Nesse sentido, mais acesso não significa necessariamente maior domínio das informações produzidas, mas pode gerar um efeito contrário, o de afogamento e até de impotência diante do imenso volume de notícias e instruções que facilmente se apresentam aos usuários da rede mundial de computadores.

O crescimento da produção textual multilíngue em meio eletrônico responde pelo aumento da demanda por traduções em todo o mundo. Pérez (2001) relaciona as transformações pelas quais passa o mercado contemporâneo de traduções a uma espécie de "revolução industrial", em que se verifica um movimento progressivo em direção à automação das atividades do tradutor, visando especialmente à redução de custos e prazos, e à divisão do trabalho em uma equipe de tradutores atuantes em diferentes pontos do globo e conectados eletronicamente pela internet. Esse fato tem sido observado especialmente na indústria da localização, responsável pela tradução e adaptação linguística e cultural de materiais em formato eletrônicos (softwares, páginas da internet, jogos e diversos e produtos de alta tecnologia) para os mercados específicos em que serão introduzidos e comercializados. Para atuar nesse setor, que tem como máxima o imediatismo de produção dos materiais textuais que o compóe, o tradutor necessita munir-se de ferramentas que lhe tornem dinâmico na conclusão de seus serviços e que lhe possibilitem alcançar uniformidade terminológica e fraseológica na produção final.

Manuais de estilo e programas específicos para controlar a terminologia e a composição dos textos de origem são bastante utilizados na fase de elaboração de originais a serem localizados, sempre visando a reduzir custos e prazo durante a etapa de tradução. Além de garantir o cumprimento dos prazos de entrega do produto final, o uso simplificado da língua tornaria possível também seu processamento semiautomático por meio de sistemas de memórias de tradução, auxiliando, em especial, a padronização de projetos de tradução desenvolvidos por vários tradutores.

Considerando que a maioria dos produtos e serviços localizados é produzida em língua inglesa, frequentemente padronizada por regras determinadas de composição dos textos de origem, o trabalho de tradução 
é concebido pelo setor como uma operação de busca e recuperação de equivalentes entre uma língua inglesa "neutra" e as outras línguas.

Este trabalho analisa algumas das relações que resultam do emprego de sistemas de memórias pelo tradutor. Tomando por base a produção de traduções para a indústria de localização, examina-se a extensão da responsabilidade do tradutor que desenvolve trabalhos parcialmente automatizados, assim como algumas das relações resultantes entre essa prática e a visão desse profissional por contratantes de seu serviço.

\section{Algumas Relações Resultantes do uso de sistemas de memórias de TRADUÇÃO PARA DINAMIZAR A PRODUÇÃO TRADUTÓRIA}

Alguns dos atributos mais importantes dos sistemas de memórias de tradução são os recursos de busca, comparação e reaproveitamento, ainda que parcial, de trechos de traduções anteriores (denominados "segmentos" na literatura), constituindo um grande auxílio para o tradutor que lida com extensos volumes de textos sob a exigência de entrega do produto final em prazos exíguos. Para o contratante de serviços de tradução, esses sistemas seriam uma maneira de controlar a produção tradutória, aproveitar traduções anteriores e restringir a remuneração do tradutor a ocorrências terminológicas e fraseológicas inéditas.

O uso dessas ferramentas também oferece a possibilidade de serem realizadas alterações e atualizações nas traduções de forma rápida e a baixos custos. A transitoriedade da informação estimula a busca pelo reaproveitamento de trechos de traduções anteriores. Na maioria dos casos, os conteúdos das memórias provêm de bancos de dados formados a partir de traduções elaboradas por outros tradutores em outros trabalhos, sendo cada vez mais raras as situações em que o tradutor executa integralmente a pesquisa e a adequação terminológicas para a tradução que desenvolve. Um exemplo de como a comunicação eletrônica possibilita a divisão de um trabalho entre vários "intermediários" é apresentado por Biau Gil e Pym:

o cliente pode querer comercializar seu produto em 15 línguas europeias. Contrata-se uma empresa de marketing, que contrata um prestador de serviços linguísticos, que contrata uma série de agentes comerciais para cada língua, que passam o trabalho para uma série de firmas de tradução, que passam os textos para os tradutores, em geral, freelancers. Nesse tipo de sistema, o cliente pode pagar até quatro vezes o que os próprios tradutores estão recebendo por página traduzida (BIAU GIL; PYM, 2006, p. 7). 
A divisão de tarefas nos projetos de traduções descrita pelos autores é exemplar da pulverização da responsabilidade tanto na indústria de localização como em projetos de revisão ou atualização de textos técnicos (manuais, por exemplo), com grande frequência de repetições. Em razão do exíguo tempo com que projetos de tradução contam para serem finalizados e graças à facilidade tecnológica de comunicação e divisão de tarefas, tradutores e outros profissionais, trabalhando em diferentes locais do mundo, encarregam-se de etapas distintas da produção desses materiais. Uma das consequências dessa setorização do trabalho seria o isolamento do tradutor que, por se encontrar, muitas vezes, distante do cliente final e do contexto geral dos textos com que trabalha, acaba limitando sua pesquisa ao banco de dados da memória (ou ao glossário fornecido pelo cliente) e direcionando esforços quase exclusivamente às "listas de frases" que lhe cabem traduzir, um trabalho que pode isolar e desumanizar a atuação do tradutor, segundo Biau Gil e Pym (2006, p. 7).

Outro efeito dessa divisão de trabalhos seria a alienação dos direitos autorais por parte do tradutor, visto que, da mesma forma que este recebe o banco de dados para "alavancar" seu trabalho, dele também se espera a provisão do banco de dados formado a partir do trabalho realizado. Contratantes de serviços de tradução defendem sua exclusividade de acesso aos dados terminológicos reunidos a partir de um trabalho contratado. Por se considerarem proprietários desse "subproduto" da tradução, em geral, exigem que lhes sejam repassados os dados terminológicos juntamente com a tradução. Esses dados são usados em trabalhos posteriores com o intuito de reduzir custos de tradução, na medida em que possibilitam o aproveitamento de correspondências estabelecidas, as quais são organizadas em "unidades de tradução". Pela perspectiva do contratante, uma tradução deveria ser remunerada uma única vez, ou seja, a partir do momento em que um segmento for traduzido e reocorrer em outros textos, não deveria ser remunerado integralmente, independentemente do contexto de que ela vier fazer parte. Como explicam Biau Gil e Pym,

a possibilidade de reutilizar traduções anteriores significa que os clientes solicitam que os tradutores trabalhem com sistemas de memórias de tradução e, depois, reduzem seus honorários. Quanto mais correspondências exatas e parciais existirem (segmentos iguais ou semelhantes já traduzidos e incluídos no banco de dados), menos eles pagam. Esse fato incita os tradutores a trabalhar rápido e, em geral, sem analisar os segmentos anteriormente traduzidos, com queda correspondente na qualidade (BIAU GIL; PYM, 2006, p. 10). 
Pela perspectiva do contratante de serviços de tradução, o banco de dados seria fornecido exclusivamente para aumentar o rendimento de um trabalho e pelo controle terminológico, determina-se a remuneração total ou fracionada do trabalho do tradutor, de acordo com o índice de reaproveitamento do conteúdo do banco. Uma vez que a prática consiste em remunerar a tradução de um segmento somente uma vez, a tendência é que o tradutor se concentre naqueles segmentos que não tenham sido antes traduzidos e que são integralmente recompensados.

A conclusão de uma tradução auxiliada por sistemas de memórias resulta na produção e no armazenamento de novos segmentos no banco de dados, comumente fornecido com o trabalho traduzido. A exigência de fornecimento do produto da tradução com os dados compilados com base no trabalho desenvolvido acaba banalizando e até extinguindo a propriedade intelectual, tanto por parte do cliente como do tradutor.

O tradutor abdica do produto da pesquisa terminológica realizada para um trabalho de tradução, assim como abre mão do seu estilo de escrita. A memória fornecida com a tradução realizada é, quase sempre, reutilizada em outros trabalhos possivelmente elaborados por outros tradutores que, por sua vez, acabam sendo obrigados a adotar as opções de tradução, e até o estilo de escrita, de tradutores anteriores a eles.

Já o cliente que fornece ao tradutor a memória para um trabalho visando a agilizá-lo e reduzir seus custos pode estar abrindo espaço para que uma terminologia desenvolvida especificamente para um produto a ser lançado seja facilmente acessada por empresas concorrentes. Para evitar quebra de sigilo, é praxe clientes celebrarem acordos de confidencialidade com os tradutores contratados. Entretanto, devido à facilidade e à rapidez com que a informação em formato digital pode ser fragmentada e compartilhada, torna-se complexo e, até impossível, impedir sua disseminação.

Visando a proteger as informações que recebem para o desenvolvimento dos trabalhos envolvidos na localização de um produto, é prática comum das agências limitar o acesso dos tradutores contratados ao banco de dados. A maioria permite que os tradutores conheçam somente as unidades de tradução que utilizarão e os fazem assinar contratos de confidencialidade. Grande parte das agências também adota critérios para a divisão de trabalhos, incluindo a contratação de gerentes de projetos de tradução e a segmentação do material de origem entre vários tradutores, para controlar a produção de seus prestadores de serviços e restringir o domínio desses profissionais sobre o projeto como um todo.

Tanto contratantes de serviços de tradução quanto as agências que prestam esses serviços são contrários à divulgação total de conteúdos dos bancos de dados dos sistemas de memórias aos tradutores que executam 
serviços contratados. Aos tradutores caberia usufruir de uma memória, quando fornecida antes de início de um trabalho, somente para a execução da tradução, e disponibilizar as unidades de tradução resultantes de seu trabalho quando o mesmo é entregue. As memórias transmitidas pelos tradutores contratados são acrescidas ao banco de dados das agências, ou do cliente, que passarão a deter a propriedade de seus conteúdos e a estipular a remuneração por suas reocorrências em trabalhos futuros.

De um ângulo oposto, tradutores autônomos defendem e praticam o intercâmbio de dados entre colegas de profissão. O compartilhamento de unidades de tradução seria uma maneira de incrementar o volume de segmentos armazenados nas memórias de tradutores autônomos e as chances de ganho de tempo nos serviços prestados pelo aproveitamento de traduções já realizadas por outros tradutores. Essa é uma das estratégias de que muitos profissionais têm se valido para adquirir competitividade em relação às extensas memórias mantidas e continuamente expandidas pelas agências de tradução e localização. Questões como a confidencialidade dos trabalhos que realizam não parecem coibir essa prática, pois, como demonstra uma pesquisa desenvolvida por Suzanne Topping (2000), consultora norte-americana em serviços de localização, muitos tradutores argumentam que a descontextualização das unidades de tradução compartilhadas os isentaria do compromisso de sigilo com os clientes. Como defendem, não seria possível exportar um texto coerente a partir de um banco de dados de um sistema de memórias.

Por outro lado, existem tradutores que não consideram o intercâmbio de bancos de dados uma forma de incremento à sua produtividade. Conforme defendem, para promover a recuperação de trechos de traduções anteriores, seria necessário adotar um estilo de escrita em tradução muito semelhante àquela da memória de referência.

A maneira como os sistemas de memórias são descritos em seus manuais e o modo como as campanhas de marketing os promovem constroem a concepção de que a memória oferece nada mais que um rol de segmentos descombinados, extraídos de diferentes contextos, e que, dispostos em duas línguas e por meio de um sistema automático, devem possibilitar o máximo de reaproveitamento em trabalhos afins. Nesse contexto, o trabalho do tradutor é tratado de forma bastante simplista, segundo a qual o cumprimento das orientações de uso dos sistemas de memórias garantiria eficácia e bons resultados à produção tradutória. Caberia ao tradutor adequar os segmentos reapresentados a novos textos, editando-os de forma a também gerarem novas possibilidades de reutilização. Fecha-se assim o ciclo que Bédard (2000, p. 42), tradutor e pesquisador em ferramentas eletrônicas de auxílio à tradução, denomina de "reciclabilidade de frases", cuja máxima estaria na "simetria quantitativa" e "a primeira instrução é traduzir uma frase por 
outra frase - raramente por duas e nunca por nenhuma". A limitação da correspondência biunívoca reafirma-se nos sistemas de memórias na medida em que, ao segmentarem o texto a ser traduzido para compará-lo às unidades de tradução armazenadas, privam o tradutor de uma visão geral do texto, sem as demarcações artificialmente encerradas por ponto final, dois pontos ou ponto e vírgula configuradas no recurso de segmentação. Para Bédard, a automatização da tradução, ainda que parcial e passível de controle pelo tradutor, baseia-se em uma noção simplista do trabalho do tradutor que, como defende, constitui também uma forma de escritura, que comunica uma mensagem e na qual "as palavras são um meio, e não um fim em si" (BÉDARD, 2000, p. 42).

A crítica de Bédard está no engessamento que os sistemas de memória impõem à maneira do tradutor reconstruir a mensagem na língua da tradução. Como explica, o tradutor, sem o uso dessa ferramenta, pode optar por reelaborar as frases do texto traduzido de modo diferente do texto de origem. Entretanto, com o auxílio dos sistemas de memória,

se o tradutor articula as frases de sua tradução de modo que seja exatamente a mesma do texto original, é ao preço de um certo grau de mediocridade estilística e comunicacional ou, ainda, de um esforço indevido de sua parte para respeitar uma estrutura, afinal de contas, artificial. Além do mais, o tradutor sofre, de certo modo, uma "deformação profissional" que o leva, perante um parágrafo, a ver não o desenvolvimento de uma ideia, mas uma simples coleção de frases (BÉDARD, 2000, p. 44).

A coesão entre as frases de um texto em uma língua, elaborada por recursos como de coordenação e subordinação, elipses, omissões, pronomes e outros dêiticos, desfaz-se conforme o tradutor se empenha em produzir segmentos de origem simétricos àqueles de origem para garantir o bom desempenho do sistema de memória. Uma possível exacerbação do efeito do tratamento do texto de forma fragmentada, por meio de segmentos descontínuos, conjuga o intercâmbio de memórias entre tradutores e os esforços para reaproveitamento desses conteúdos como forma de acelerar o trabalho. Segmentos provindos de diferentes contextos, pareados com as traduções realizadas por diferentes tradutores, são reunidos e formam o que Bédard (2000, p. 45) qualifica como uma "salada de frases". Essa operação para utilização da memória iria de encontro a uma das principais justificativas para seu uso: a coerência textual. Sempre que o tradutor se esforça para reaproveitar ao máximo o conteúdo da memória de que dispõe, ele pode estar correndo o risco de empregar equivocadamente termos, trechos de 
segmentos e até frases inteiras no texto traduzido. Ademais, se a memória utilizada tiver sido formada a partir da produção de outros tradutores, os segmentos nela contidos não deixarão de refletir os diferentes estilos de seus tradutores, possivelmente resultando em um texto traduzido repleto de disparidades, definidas por Deslile (2006, p. 162) como "incoerências estilísticas e discordâncias que afetam o trabalho traduzido. Quando comparada ao original, a tradução demonstra falta de unidade linguística, estilística e tonal, entre outras".

A memória, como referência mais acessível e, muitas vezes, oferecida como a base mais confiável ao tradutor, tem efeito em sua produção. Como salientam Bowker e Barlow (2008), mesmo que uma sugestão recuperada da memória não seja a mais apropriada para o tradutor para a tradução de um determinado segmento, ela pode acabar influenciando suas escolhas na elaboração da tradução, pois, como defendem,

após o tradutor ter visto uma sugestão do banco de dados, pode ser difícil pensar em outra forma de expressar aquele pensamento; assim, ele pode utilizar a tradução sugerida mesmo se ela não se adequar de modo coerente ao texto como um todo (BOWKER; BARLOW, 2008, p. 79).

A pressão dos prazos a que o tradutor se submete para realizar um trabalho pode constituir um agravante para a adoção de sugestões apresentadas pela memória que, à primeira vista, pareçam suficientemente apropriadas no contexto restrito pela segmentação em que o tradutor trabalha. A falta de experiência técnica do tradutor com o sistema que utiliza também pode interferir nas escolhas que fará para elaborar o texto traduzido, da mesma maneira que nos casos em que o tradutor não conta com conhecimento suficiente da especialidade em que esteja atuando.

o modo como o tradutor é condicionado a orientar seu trabalho de forma a garantir o uso eficiente dos sistemas de memórias reflete a concepção contemporânea de tradução. A descrição da prática de tradução de segmentos delimitados de modo simétrico e autônomo, a prescrição da adoção de opções terminológicas pré-definidas e a orientação em ajustar segmentos já traduzidos e recuperados automaticamente a um novo contexto revelam uma visão mecanicista da prática tradutória. Se considerarmos como possível a visão futurística que Esselink (diretor de uma empresa prestadora de serviços de localização e também consultor nessa área) projeta para a indústria de localização, a tendência é que se produzam cada vez mais traduções a um ritmo industrial. Como prevê, na próspera indústria da localização, os efeitos da segmentação do mercado serão sentidos pelo estreitamento da atuação 
do tradutor, que fará parte de uma cadeia muito maior de profissionais que se ocupam de etapas específicas do trabalho de composição textual no número de línguas de interesse comercial. Conforme vislumbra, "todos os textos serão criados, gerenciados e publicados com base em tecnologias de bancos de dados" (ESSELINK, 2000, p. 478). A exigência de conclusão dos trabalhos em prazos decrescentes fará com que "toda a informação seja extraída dos bancos de dados, processada pela memória de tradução de forma que somente o texto novo seja traduzido" (ESSELINK, 2000, p. 479).

Se concebemos o tradutor como o controlador das memórias, como concebem os projetos dos sistemas utilizados na atualidade, podemos inferir que seu domínio sobre o texto tenderá a diminuir na divisão de trabalho vislumbrada por Esselink. A base interpretativa construída pelo tradutor e sobre a qual ele desenvolve seu trabalho estará apoiada somente em partes do texto a ele designadas para tradução.

\section{Considerações FInAIS}

Quais seriam algumas das consequências da crescente disponibilização de textos de origem em meio digital, cujas traduções são contratadas e realizadas segundo as práticas descritas neste trabalho?

A mais importante pode ser a dispersão da responsabilidade do tradutor que lida com um original em constante processo de atualização e, em geral, fragmentado para possibilitar a tradução e o tratamento em equipe. Sendo o comprometimento do tradutor com o trabalho que realiza limitado também pelas ferramentas que o auxiliam, desfazem-se as relações que $o$ tradutor constrói com o texto que produz. A relação do tradutor com o texto que traduz limita-se ao pequeno espaço que lhe é permitido intervir no texto, como em situações em que o sistema que utiliza não recupera segmentos da memória, ou em que essa recuperação é parcial, exigindo a edição pelo tradutor. Essa restrição da atuação do tradutor limita também a medida de sua responsabilidade, já que não seria cabível ele responder por um trabalho com base em um texto de que só traduziu trechos e que desconhece na íntegra.

Conclui-se que os mesmos recursos designados a acelerar e a uniformizar a produção tradutória, pela segmentação do texto sendo traduzido e pela busca por correspondências na memória do sistema, podem causar o efeito inverso, uma vez que podem ser uma interferência à construção da coerência textual pelo tradutor. Quando tudo que o tradutor tem à sua frente são segmentos textuais e opções de traduções passadas, pode acabar tornando-se difícil construir uma rede de relações conceituais e semânticas no texto que traduz. 
Ao receber um trabalho parcialmente traduzido e ao partir de buscas e recuperações de trechos traduzidos armazenados em bancos de dados, e traduzidos em outras situações e por outros profissionais, o tradutor é privado de realizar suas escolhas segundo a interpretação que teria do texto na língua de origem, pois parte do texto já foi "interpretado" para ele. Nesse caso, sua responsabilidade não é só dissipada, mas também é reduzida na medida em que sua intervenção no texto é limitada e guiada pelo modo como os sistemas de memórias são empregados.

\section{REFERÊNCIAS}

BAUMAN, Z. Globalização: as consequências humanas. Tradução: Marcus Penchel. Rio de Janeiro: Zahar, 1999.

BÉDARD, C. Mémoire de traduction cherche traducteur de phrases. Traduire, n. 186, p. 41-49, 2000.

BIAU GIL, J. R.; PYM, A. Technology and translation (a pedagogical overview). In: PYM, A., A.; PEREKRESTENKO, A.; STARINK, B. Translation technology and its teaching. Tarragona, Espanha, 2006. Disponível em <http://isg.urv.es/publicity/isg/publications/technology_2006/ index.htm>. Acesso em: 22/6/2006.

BOWKER, L.; BARLOW, M. Bilingual concordancers and translation memories: a comparative evaluation. In: YUSTE RODRIGO, E. (Ed.). Topics in Language Resources for Translation and Localisation. Amsterdam: John Benjamins, 2008. p. 70-83.

DELISLE, J. Criticizing translations: the notion of disparity. In: BOWKER, L. (Ed.). Lexicography, terminology and translation: text-based studies in honour of Ingrid Meyer. Ottawa: University of Ottawa Press, 2006. p. 159-173.

ESSELINK, Bert. A practical guide to localization. Amsterdam: John Benjamins, 2000.

PÉREZ, C. R. From novelty to ubiquity: computers and translation at the close of the industrial age. Translation Journal, v. 5, n. 1, jan. 2001. Disponível em: <http://www.accurapid.com/ journal >. Acesso em: 14/3/2012.

TOPPING, Suzanne. Sharing translation database information: considerations for developing an ethical and viable exchange of data. Multilingual Computing and Technology, v. 5, n. 11, p. 59-61, 2000.

Submetido em: 29/04/2012

Aceito em: 03/08/2012 